\title{
OY-TES-1 may regulate the malignant behavior of liver cancer via NANOG, CD9, CCND2 and CDCA3: A bioinformatic analysis combine with RNAi and oligonucleotide microarray
}

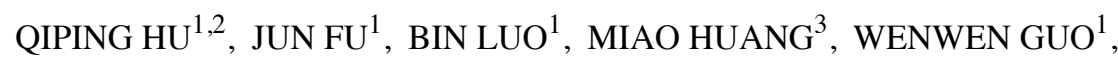 \\ YONGDA LIN $^{1}$, XIAOXUN XIE $^{1}$ and SHAOWEN XIAO ${ }^{4}$
}

\begin{abstract}
Departments of ${ }^{1}$ Histology and Embryology, and ${ }^{2}$ Cell Biology and Genetics, School of Pre-Clinical Medicine, Guangxi Medical University; ${ }^{3}$ Department of Radiology, Affiliated Cancer Hospital of Guangxi Medical University; ${ }^{4}$ Department of Neurosurgery, First Affiliated Hospital of Guangxi Medical University, Nanning, Guangxi 530021, P.R. China
\end{abstract}

Received November 25, 2014; Accepted January 26, 2015

DOI: $10.3892 /$ or.2015.3792

\begin{abstract}
Given its tumor-specific expression, including liver cancer, OY-TES-1 is a potential molecular marker for the diagnosis and immunotherapy of liver cancers. However, investigations of the mechanisms and the role of OY-TES-1 in liver cancer are rare. In the present study, based on a comprehensive bioinformatic analysis combined with RNA interference (RNAi) and oligonucleotide microarray, we report for the first time that downregulation of OY-TES-1 resulted in significant changes in expression of NANOG, CD9, CCND2 and CDCA3 in the liver cancer cell line BEL-7404. NANOG, CD9, CCND2 and CDCA3 may be involved in cell proliferation, migration, invasion and apoptosis, yet also may be functionally related to each other and OY-TES-1. Among these molecules, we identified that NANOG, containing a Kazal-2 binding motif and homeobox, may be the most likely candidate protein interacting with OY-TES-1 in liver cancer. Thus, the present study may provide important information for further investigation of the roles of OY-TES-1 in liver cancer.
\end{abstract}

\section{Introduction}

Surgical resection is the primary mode of choice in the treatment of liver cancer, while the 5-year recurrence rate after

Correspondence to: Dr Xiaoxun Xie, Department of Histology and Embryology, School of Pre-Clinical Medicine, Guangxi Medical University, 22 Shuangyong Road, Nanning, Guangxi 530021, P.R. China E-mail: xiaoxunxie@gmail.com

Dr Shaowen Xiao, Department of Neurosurgery, First Affiliated Hospital of Guangxi Medical University, 22 Shuangyong Road, Nanning, Guangxi 530021, P.R. China

E-mail: xsw57@yahoo.com

Key words: OY-TES-1, bioinformatics, RNAi, oligonucleotide microarray, NANOG, CD9, liver cancer resection is as high as $35.4-43.5 \%$ (1). The poor prognosis associated with liver cancer has prompted the identification and development of new diagnostic markers and therapeutic strategies. Immunotherapy is a potentially attractive option for patients with liver cancer. Cancer/testis (CT) antigens are potential immunotherapeutic targets in many types of cancers including liver cancer due to their expression pattern, which is restrictively expressed in the testes, yet aberrantly expressed by a variety of malignancies (2-8). OY-TES-1 has been defined as the 23rd member of the CT antigen family, called CT23 (9-12). OY-TES-1 was originally identified to be the human homologue of pro-acrosin binding protein (ACRBP), a tyrosine phosphorylated protein related to capacitation, the sp32 precursor in mouse (13). Spontaneous humoral response against OY-TES-1 has been detected in patients with different tumors including liver cancer (9). An HLA-A24-binding OY-TES-1 peptide recognized by CD8 T cells was identified, and T-cell cytotoxicity was observed against an OY-TES-1 mRNA-expressing lung tumor cell line in vitro (14). The above studies imply that OY-TES-1 is an attractive target for antigenspecific immunotherapy in cancers due to its immunogenic traits in humans $(9,14)$. In another study in ovarian cancer cells, a mitotic spindle protein NuMA was identified as an ACRBPinteracting protein (12). ACRBP depletion resulted in mitotic errors and reduced proliferative fitness that could be rescued by NuMA co-depletion. This indicates that ACRBP could normalize the perturbed mitotic infrastructure responsible for disease-promoting genetic variation. In our previous report, we demonstrated that OY-TES-1 was expressed in human mesenchymal stem cells (MSCs) at both the mRNA and protein levels, and downregulation of OY-TES-1 expression in these MSCs caused cell growth inhibition, cell cycle arrest, apoptosis induction and migration ability attenuation (15). However, whether OY-TES-1 is involved in the biological function of liver cancer remains undetermined. In the present study, we applied bioinformatic analysis combined with a molecular biology assay to investigate the biological function and protein interaction of OY-TES-1 in liver cancer. Our data indicated that OY-TES-1 regulates biological processes of liver cancer cells via NANOG, CD9, CCND2 and CDCA3. 


\section{Materials and methods}

Motif and domain-domain interaction analysis. The motif analysis of OY-TES-1 protein was performed with SSDB Motif Search in Kyoto Encyclopedia of Genes and Genomes (KEGG) online database (http://www.kegg.jp/). The protein domain interactions were analyzed by DOMINE online database (16) (http://domine.utdallas.edu/cgi-bin/Domine) and the Pfam protein families database (17), respectively. KEGG is a database resource for understanding high-level functions and utilities of the biological system from molecular-level information, particularly large-scale molecular datasets generated by genome sequencing and other high-throughput experimental technologies. With KEGG motif search, a domain of unknown function with peptide fragment usually can be found (18). DOMINE is a database of known and predicted protein domain (domain-domain) interactions, which are predicted by 13 different computational approaches using Pfam domain definitions. DOMINE contains a total of 26,219 domaindomain interactions (among 5,410 domains) out of which 6,634 are inferred from PDB entries, of which 2,989 interactions are high-confidence predictions (HCPs) $(16,17)$.

Co-expressing gene analysis in liver cancer through ONCOMINE. To identify significant OY-TES-1-co-expressing genes in liver cancer, we searched for all relevant, publically available microarray datasets in online cancer microarray gene expression database, ONCOMINE (https://www.ONCOMINE. org/resource/main.html) (19). ONCOMINE database is a bioinformatics initiative aimed at collecting, standardizing, analyzing and delivering cancer transcriptome data to the biomedical research community. The analysis has identified the genes, pathways and networks deregulated across 18,000 cancer gene expression microarrays, spanning the majority of cancer types and subtypes (19). As there are often many hundreds of tumor samples/microarrays within a single multi-array result from co-expressing genes can be analyzed. ONCOMINE database provides a potentially significant list of co-expressing genes, which is important to define pathways in which the gene of interest is involved (20).

Co-expressing gene annotation through gene ontology $(G O)$ annotator. GO annotator uses text-mining methods to extract GO terms from scientific studies and provides this information along with a GO term from an uncurated annotation; thus, it provides not only facts but also their evidence (21). Based on the GO annotation, we searched each proliferation, migration, invasion or apoptosis GO term for the genes with high correlation and frequency to OY-TES-1 co-expression in the GO database.

Co-expressing gene literature co-occurrence through COREMINE and PubMed.TheOY-TES-1-co-expressing genes with GO terms of cell proliferation, adhesion, migration and apoptosis in liver cancer were fed to a literature co-occurrence tool-COREMINE online tool (http://www.coremine.com/ medical/\#search) (22). COREMINE medical is a gene/protein database and web-based tool for literature mining. It develops automated extraction of experimental and theoretical knowledge of biomedicine from publicly available gene and text databases to create a gene-to-gene co-citation network for human genes in MEDLINE records (22). The systematic search of the literature was performed with PubMed for studies addressing association among liver cancer, OY-TES-1 and OY-TES-1 interacting proteins.

Oligonucleotide microarray analysis combined with RNAi. OY-TES-1 was downregulated in the liver cancer cell line BEL-7404 using small interfering RNA (siRNA) with X-tremeGENE siRNA transfection reagent (Roche Diagnostics). OY-TES-1 siRNA and a scrambled siRNA were synthesized by Shanghai GenePharma Co., Ltd. The sequences of the siRNAs and experimental procedure were previously described by Cen et al (15). Total RNA extracted from non-siRNA-treated cells and siRNA-OYTES-1-treated cells was used for genome-wide expression analysis with the Human Whole Genome 6x44K Microarray (Agilent Technologies, Inc., Santa Clara, CA, USA) according to the manufacturer's protocol (23). Data quality check and analysis were conducted using SBC analysis system (Agilent Technologies). p-value was calculated when duplicates were used in the experiment, and differentially expressed genes were selected by p-value $(<0.05)(24)$.

Generation of biological interaction network through GeneMANIA. Candidate genes selected from the oligonucleotide microarray assay above were fed into a curated protein interaction network system-GeneMANIA (http:// www.genemania.org/), which is a fast web-based tool and database for predicting gene function based on multiple networks derived from different genomic or proteomic data/ sources with great accuracy (25). With the GeneMANIA a gene/protein-gene/protein interaction network of OY-TES-1 was generated.

\section{Results}

Four motifs were identified in OY-TES-1. Following a search for 'OY-TES-1' in the KEGG online database, four motifs, Kazal-1 and -2, PBP-sp32 and TFIIF- $\alpha$, were found in human OY-TES-1 on the dataset of hsa:84519 (Table I; Fig. 1). The Kazal motif contains two patterns, Kazal-1 and -2 . The amino terminal segment of both Kazal motifs can bind to the active site of target proteases resulting in functional inhibition (Table I). The family of Kazal-1 inhibitor proteins inhibits serine peptidases of the S1 family, such as trypsin and elastase $(26,27)$, while the family of Kazal-2 inhibitor proteins inhibits serine peptidases of MEROPS, such as I1, I2, I17 and I31. However, Kazal-like domains are also seen in the extracellular part of agrins, which are unknown to be protease inhibitor (28). TFIIF- $\alpha$, a subunit of transcription initiation factor IIF, or RNA polymerase II-associating protein 74 (RAP74) is the large subunit of transcription factor IIF. By interacting with the proteins containing interacted motifs as summarized in Table I, TFIIF- $\alpha$ plays an essential role in accurate initiation and stimulates elongation by RNA polymerase II (29). PBP-sp32 is a sperm-specific domain involved in packaging acrosin zymogen into acrosomal matrix (30). In general, OY-TES-1 interacts with the proteins containing TFIIF- $\alpha$, Kazal-1 and -2 motifs or the proteins 
Table I. The motifs of OY-TES-1 and NANOG, interacted motifs and motif-shared proteins according to database search ${ }^{\mathrm{a}}$.

\begin{tabular}{|c|c|c|c|c|c|c|}
\hline Protein & Motif id & Location & Definition & E-value & Interacted motif & Motif-shared proteins \\
\hline \multirow[t]{4}{*}{ OY-TES-1 } & pf:Kazal_1 & $474-504$ & $\begin{array}{l}\text { Kazal-type } \\
\text { serine } \\
\text { protease } \\
\text { inhibitor } \\
\text { domain }\end{array}$ & 0.05 & $\begin{array}{l}\text { TGF- } \beta, \text { Kazal-1, } \\
\text { Peptidase-S8, Trypsin, } \\
\text { FOLN, SPARC-Ca_bdg, } \\
\text { efhand, Laminin-EGF, } \\
\text { Thyroglobulin_1, EGF, } \\
\text { Kunitz-BPTI, ig, } \\
\text { Laminin-G_1, } \\
\text { Ldl_recept_a, Sushi, } \\
\text { TSP-1, zf-C }{ }_{2} \mathrm{H}_{2}, \\
\text { SRCR, PDZ, SEA, } \\
\text { MACPF, OATP }\end{array}$ & $\begin{array}{l}\text { AGRIN, CPAMD8, FST, } \\
\text { FSTL3, FSTL4, FSTL5, } \\
\text {,IGFBPL1, SMOC1, SPARC, } \\
\text { SPARCL1, SPINK1, } \\
\text { SPINK2, SPINK4, } \\
\text { SPINK5, SPINK5L2, } \\
\text { SPINK5L3, SPINK6, } \\
\text { SPINK7, SPINK9, } \\
\text { TMEFF1, TMEFF2 }\end{array}$ \\
\hline & pf:Kazal_2 & $473-506$ & $\begin{array}{l}\text { Kazal-type } \\
\text { serine } \\
\text { protease } \\
\text { inhibitor } \\
\text { domain }\end{array}$ & 0.0075 & $\begin{array}{l}\text { TGF- } \beta \text {, Trypsin, } \\
\text { Kazal-2, BTB, } \\
\text { Homeobox, } \\
\text { Arrestin_N, LIM, } \\
\text { Arrestin-C }\end{array}$ & $\begin{array}{l}\text { C6, CFI, FSTL1, FSTL3, } \\
\text { HTRA1, HTRA3, HTRA4, } \\
\text { IGFBP7, KAZALD1, } \\
\text { LST3, RECK, SLC21A8, } \\
\text { SLCO1A2, SLCO1B1, } \\
\text { SLCO1B3, SLCO1C1, } \\
\text { SLCO2A1, SLCO3A1, } \\
\text { SLCO4A1, SLCO4C1, } \\
\text { SLCO5A1, SLCO6A1, } \\
\text { SMOC2, SPINK5, SPOCK1, } \\
\text { SPOCK2, SPOCK3, } \\
\text { WFIKKN1, WFIKKN2 }\end{array}$ \\
\hline & pf:TFIIF_ $\alpha$ & $197-263$ & $\begin{array}{l}\text { Transcription } \\
\text { initiation } \\
\text { factor IIF, } \\
\alpha \text { subunit } \\
(\text { TFIIF- } \alpha)\end{array}$ & 0.13 & $\begin{array}{l}\text { TFIIF_ } \beta, \text { FCP1_C, } \\
\text { Tax, FlhD, } \\
\text { Ribosomal_L7Ae, } \\
\text { HNF-1_N, TFIIF_ } \alpha\end{array}$ & TFIIF \\
\hline & pf:PBP_sp32 & $1-240$ & $\begin{array}{l}\text { Proacrosin } \\
\text { binding } \\
\text { protein } \\
\text { sp32 }\end{array}$ & $9.30 \mathrm{e}-135$ & Unknown & OY-TES-1 (sp32/ACRBP) \\
\hline \multirow[t]{2}{*}{ NANOG } & pf:Homeobox & $97-152$ & $\begin{array}{l}\text { Homeobox } \\
\text { domain }\end{array}$ & $7.80 \mathrm{E}-19$ & $\begin{array}{l}\text { Homeobox, Pou, } \\
\text { SRF-TF, SBP_bac_1, } \\
\text { CUT, HNF-1B_C, } \\
\text { HNF-1_N, PD-C2-AF1, } \\
\text { HLH, Pkinase, } \\
\text { RRM_1, zf-C2H2, } \\
\text { PAX, WD40, MH2, } \\
\text { EGF, Kazal_2 }\end{array}$ & Pou family \\
\hline & pf:Homez & $110-147$ & $\begin{array}{l}\text { Homeodomain } \\
\text { leucine-zipper } \\
\text { encoding, } \\
\text { Homez }\end{array}$ & 0.00024 & Unknown & Unknown \\
\hline
\end{tabular}

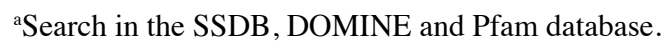

containing the interacted motifs of these 3 motifs. Thus, through these interactions, OY-TES-1 may perform its functions in regulating the biological behavior of tumor cells.
Sixty genes were found to co-express with OY-TES-1 in liver cancer. To investigate OY-TES-1-co-expressing genes in liver cancer, we queried the ONCOMINE database using 


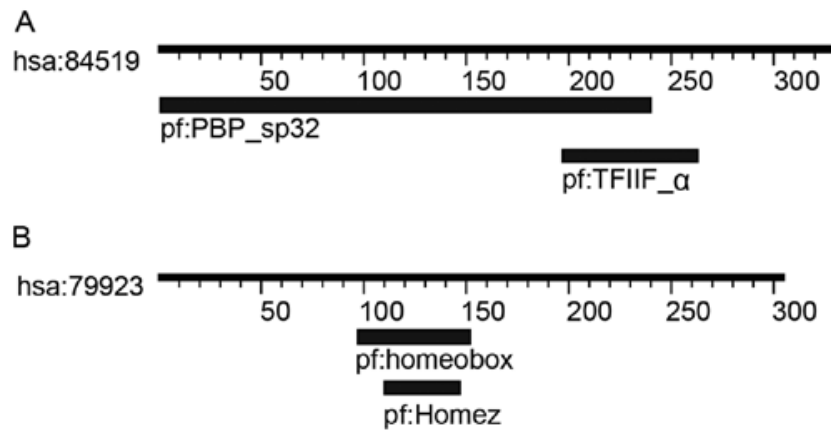

Figure 1. The motifs contained in (A) OY-TES-1 and (B) NANOG protein according to SSDB Motif Search. Black bars represent the location of each motif.

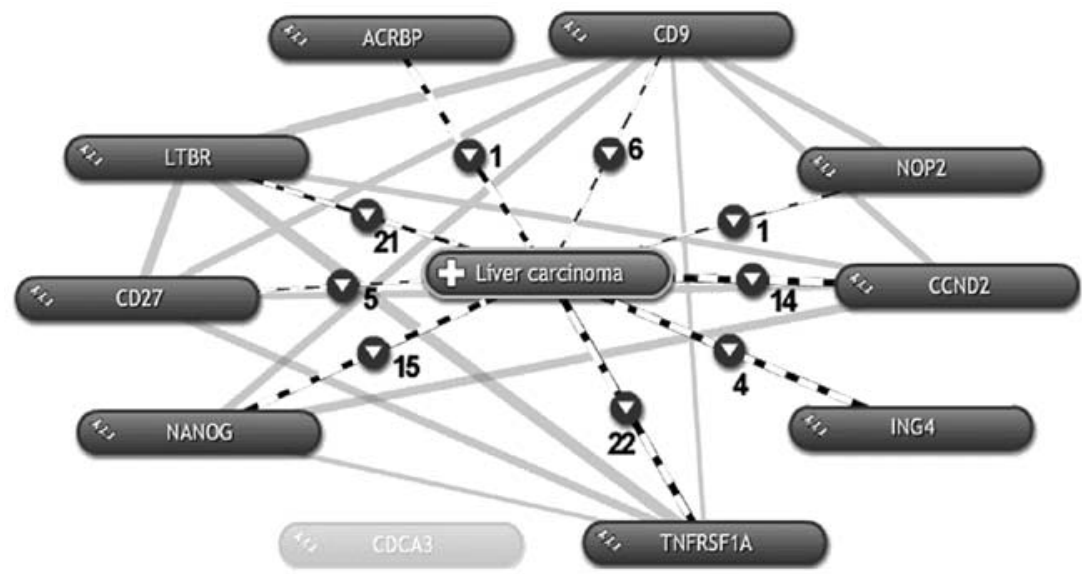

Figure 2. The co-occurrence analysis of OY-TES-1 (ACRBP) and its co-expressing genes to the exact key word expression 'liver carcinoma (aliases of 'liver cancer')' by COREMINE online tool search. Zebra line indicates the co-occurrence of the genes to the key word 'liver carcinoma', and the number near the line is the number of co-occurrences between the gene and 'liver carcinoma'; the light gray line indicates the co-occurrence of the genes between each other. ACRBP, acrosin binding protein.

a concept 'co-expression genes with OY-TES-1 expression in liver cancer'. There was a list of 5,051 genes in 9 datasets, namely Liver (Liao)-Cluster ID n9273 (17 genes); Multi-cancer (Beroukhim)-Cluster ID n9385 (85 genes), Cell Line (Rothenberg)-Cluster ID n9276 (207 genes), Cell Line (Wooster 2)-Cluster ID n9229 (209 genes), Cell Line (Barretina 2)-Cluster ID n9313 (229 genes), Liver cancer (Bittner Multi-cancer, 978 genes), Liver cancer (Wooster Cell Line 2, 1,875 genes), Liver cancer (Barretina Cell Line, 1,957 genes) and Liver cancer (Bittner Multi-cancer, 1,957 genes). As listed in Table II, 60 genes were co-expressed with OY-TES-1 at least in 5 of 9 datasets mentioned above, and the correlation between those genes and OY-TES-1 was $>0.900$.

Nine OY-TES-1 co-expressing genes may regulate biological processes. As the 60 genes identified above showed a correlation with OY-TES-1, we further predicted their function through GO annotator and COREMINE online tool search. As listed in Table III, we identified 9 genes: CD9 molecule (CD9), cyclin D2 (CCND2), CD27 molecule (CD27), cell division cycle-associated protein (CDCA3), inhibitor of growth family, member 4 (ING4), lymphotoxin- $\beta$ receptor (LTBR), homeobox transcription factor Nanog (NANOG), nucleolar protein 2 homolog (NOP2) and tumor necrosis factor receptor superfamily, member 1A (TNFRSF1A). These genes are involved in cell proliferation, adhesion, migration and/or apoptosis.
Eight OY-TES-1 co-expressing genes are co-occurring in liver cancer. According to the above search, 9 of the co-expressing OY-TES-1 genes are involved in the biological behavior of cells, but whether they are related to liver cancer remains unknown. Thus, these 9 genes and OY-TES-1 were further fed to COREMINE online tool search using 'liver carcinoma' as a key word. As shown in Fig. 2, co-occurrence with liver cancer was demonstrated for OY-TES-1 and 8 of the 9 genes except for CDCA3, and these 8 genes also co-occur with each other. Among those 8 genes, CD27, ING4, LTBR and TNFRSF1A are known to be involved in apoptosis; CD27 negatively regulates the apoptotic process (31-34), while ING4 (35-37), LTBR (38) and TNFRSF1A (39) positively regulate the apoptotic process. CD9 is also considered to regulate migration and adhesion of cells $(40,41)$. In addition, CD9 and ING4 are thought to negatively regulate cell proliferation $(35,44)$. The others, CCND2 (45-51), NANOG (52-54) and NOP2 $(55,56)$, positively regulate cell proliferation. With regard to CDCA3, a $G_{1}$ phase controlling gene which prevents $G_{1}$ arrest, there is no current literature that shows that it is involved in liver cancer. However, considering that CDCA3 has a high expression frequency and a high co-expression correlation with OY-TES-1 in liver cancer datasets, further investigation of CDCA3 is needed. To date, there is no report of the involvement of OY-TES-1 in apoptosis, migration, adhesion and cell proliferation of liver cancer. We here demonstrated that 
Table II. Genes co-expressing with OY-TES-1 at least in 5 out of 9 datasets.

\begin{tabular}{|c|c|c|c|c|c|}
\hline Gene & Correlation $^{\mathrm{a}}$ & Freq $^{b}$ & Gene & Correlation & Freq \\
\hline EMG1 & $0.980 \pm 0.000$ & $7 / 9$ & CLSTN3 & $0.964 \pm 0.028$ & $5 / 9$ \\
\hline CD9 & $0.980 \pm 0.005$ & $7 / 9$ & C1RL & $0.964 \pm 0.028$ & $5 / 9$ \\
\hline ZNF384 & $0.989 \pm 0.008$ & $7 / 9$ & COPS7A & $0.990 \pm 0.009$ & $5 / 9$ \\
\hline SCNN1A & $0.971 \pm 0.014$ & $7 / 9$ & LAG3 & $0.986 \pm 0.006$ & $5 / 9$ \\
\hline C12orf53 & $0.991 \pm 0.010$ & $7 / 9$ & DPPA3 & $0.951 \pm 0.018$ & $5 / 9$ \\
\hline CLEC4A & $0.951 \pm 0.018$ & $6 / 9$ & ATN1 & $0.982 \pm 0.003$ & $5 / 9$ \\
\hline ENO2 & $0.983 \pm 0.003$ & $6 / 9$ & RIMKLB & $0.907 \pm 0.000$ & $5 / 9$ \\
\hline $\mathrm{CD} 27$ & $0.977 \pm 0.006$ & $6 / 9$ & USP5 & $0.988 \pm 0.007$ & $5 / 9$ \\
\hline MFAP5 & $0.907 \pm 0.000$ & $6 / 9$ & C12orf57 & $0.982 \pm 0.003$ & $5 / 9$ \\
\hline $\mathrm{FOXJ} 2$ & $0.951 \pm 0.018$ & $6 / 9$ & TAPBPL & $0.977 \pm 0.006$ & $5 / 9$ \\
\hline LPAR5 & $1.000 \pm 0.001$ & $6 / 9$ & C1R & $0.964 \pm 0.028$ & $5 / 9$ \\
\hline NCAPD2 & $0.977 \pm 0.006$ & $6 / 9$ & LTBR & $0.971 \pm 0.014$ & $5 / 9$ \\
\hline VAMP1 & $0.977 \pm 0.006$ & $6 / 9$ & LEPREL2 & $0.988 \pm 0.007$ & $5 / 9$ \\
\hline $\mathrm{C} 1 \mathrm{~S}$ & $0.976 \pm 0.007$ & $5 / 9$ & TPI1 & $0.988 \pm 0.007$ & $5 / 9$ \\
\hline ITFG2 & $0.861 \pm 0.015$ & $5 / 9$ & NOP2 & $0.996 \pm 0.004$ & $5 / 9$ \\
\hline ING4 & $0.997 \pm 0.004$ & $5 / 9$ & GNB3 & $0.988 \pm 0.007$ & $5 / 9$ \\
\hline PHB2 & $0.982 \pm 0.003$ & $5 / 9$ & MLF2 & $0.985 \pm 0.005$ & $5 / 9$ \\
\hline NANOG & $0.951 \pm 0.018$ & $5 / 9$ & RBP5 & $0.964 \pm 0.028$ & $5 / 9$ \\
\hline CDCA3 & $0.988 \pm 0.007$ & $5 / 9$ & LRRC23 & $0.983 \pm 0.006$ & $5 / 9$ \\
\hline PTPN6 & $0.982 \pm 0.003$ & $5 / 9$ & LPCAT3 & $0.976 \pm 0.007$ & $5 / 9$ \\
\hline CLEC4C & $0.951 \pm 0.018$ & $5 / 9$ & PLEKHG6 & $0.971 \pm 0.014$ & $5 / 9$ \\
\hline SLC2A14 & $0.922 \pm 0.009$ & $5 / 9$ & GAPDH & $0.984 \pm 0.011$ & $5 / 9$ \\
\hline TNFRSF1A & $0.971 \pm 0.014$ & $5 / 9$ & GDF3 & $0.951 \pm 0.018$ & $5 / 9$ \\
\hline AICDA & $0.907 \pm 0.000$ & $5 / 9$ & IFFO1 & $0.988 \pm 0.012$ & $5 / 9$ \\
\hline SLC2A3 & $0.922 \pm 0.009$ & $5 / 9$ & CD4 & $0.976 \pm 0.017$ & $5 / 9$ \\
\hline FAM90A1 & $0.943 \pm 0.016$ & $5 / 9$ & CHD4 & $0.999 \pm 0.001$ & $5 / 9$ \\
\hline NECAP1 & $0.951 \pm 0.018$ & $5 / 9$ & PTMS & $0.986 \pm 0.006$ & $5 / 9$ \\
\hline CCND2 & $0.956 \pm 0.022$ & $5 / 9$ & A2ML1 & $0.907 \pm 0.000$ & $5 / 9$ \\
\hline GPR162 & $0.988 \pm 0.007$ & $5 / 9$ & C3AR1 & $0.951 \pm 0.018$ & $5 / 9$ \\
\hline SPSB2 & $0.988 \pm 0.007$ & $5 / 9$ & MRPL51 & $0.977 \pm 0.006$ & $5 / 9$ \\
\hline
\end{tabular}

${ }^{\mathrm{a} C}$ Correlation (mean $\pm \mathrm{SD}$ ) between expression of the candidate genes and OY-TES-1 is $>0.900$. ${ }^{\mathrm{b}}$ Frequency of the candidate gene co-expressing with OY-TES- 1 in the 9 datasets, searched in the ONCOMINE online database.

OY-TES-1 is co-expressed with 9 genes (CD9, CCND2, ING4, CDCA3, NANOG, NOP2, CD27, LTBR and TNFRSF1A) with a high correlation and frequency, inferring that OY-TES-1 may be involved in the cell adhesion/migration regulated by CD9, cell proliferation mediated by CD9, CCND2, ING4, CDCA3, NANOG and NOP2, and apoptosis modulated by CD27, ING4, LTBR and TNFRSF1A in liver cancer, respectively.

Four candidate genes are significantly altered by OY-TES-1 downregulation. As the above results identified 9 OY-TES-1co-expressing genes with functions of cell proliferation, adhesion, migration and/or apoptosis, we further screened an oligonucleotide microarray following OY-TES-1 downregulation in a liver cancer cell line. It was found that a total of 8,870 genes were significantly altered $(\mathrm{p}<0.05)$ in the siRNA-OY-TES-1-treated cell as compared with the control. Notably, these 9 OY-TES-1 co-expressing genes (CD9, CCND2, CDCA3, NANOG, ING4, NOP2, CD27, LTBR and
TNFRSF1A) revealed a differential expression profile. CD9, CCND2 and CDCA3 were upregulated, whereas NANOG was downregulated. Another 5 genes had no expression change ( $>0.05$, Table IV). Furthermore, after searching the motif of CD9, CCND2, CDCA3 and NANOG in SSDB, DOMINE and Pfam database, an interacted motif of Kazal-2 contained in OY-TES-1, homeobox, was found in human NANOG on the dataset of hsa:79,923 (Table I; Fig. 1). Therefore, NANOG may be considered as the most likely candidate protein interacting with OY-TES-1 in liver cancers.

OY-TES-1 may be functionally related to NANOG, CD9, $C C N D 2$ and $C D C A 3$ by various interactions. Due to the unclear functions of OY-TES-1 and its co-expressing proteins, OY-TES-1, NANOG, CDCA3, CD9 and CCND2 were fed into GeneMANIA to predict their functions and interactions. As shown in Fig. 3, OY-TES-1, NANOG, CD9, CCND2 and CDCA3 were co-expressed, co-localized, physically and genet- 
Table III. The biological process annotation of OY-TES-1-co-expressing genes by GO annotator.

\begin{tabular}{|c|c|c|c|c|}
\hline Gene & GO ID & Qualified GO term & Evidence & Ref. \\
\hline \multirow[t]{2}{*}{ CD9 } & GO:0007155 & Cell adhesion & IDA & $(38)$ \\
\hline & GO:0008285 & Negative regulation of cell proliferation & IEA & No \\
\hline \multirow[t]{3}{*}{ CCND2 } & GO:0007049 & Cell cycle & IEA & No \\
\hline & GO:0045737 & Positive regulation of cyclin-dependent protein kinase activity & IDA & $(43)$ \\
\hline & GO:0051301 & Cell division & IEA & No \\
\hline \multirow[t]{4}{*}{$\mathrm{CD} 27$} & GO:0006917 & Induction of apoptosis & ISS & No \\
\hline & GO:0008588 & Release of cytoplasmic sequestered NF- $\mathrm{KB}$ & NAS & (29) \\
\hline & GO:0043066 & Negative regulation of apoptotic process & ISS & No \\
\hline & GO:0043154 & $\begin{array}{l}\text { Negative regulation of cysteine-type endopeptidase activity } \\
\text { involved in apoptotic process }\end{array}$ & IDA & $(29)$ \\
\hline \multirow[t]{2}{*}{$\mathrm{CDCA}^{\mathrm{a}}$} & GO:0007067 & Mitosis & IEA & No \\
\hline & GO:0051301 & Cell division & IEA & No \\
\hline \multirow[t]{4}{*}{ ING4 } & GO:0006915 & Apoptotic process & IDA & (33) \\
\hline & GO:0007050 & Cell cycle arrest & IDA & (33) \\
\hline & GO:0008285 & Negative regulation of cell proliferation & IDA & (33) \\
\hline & GO:0043065 & Positive regulation of apoptotic process & IDA & $(34)$ \\
\hline \multirow[t]{2}{*}{ LTBR } & GO:0006915 & Apoptotic process & IEA & No \\
\hline & GO:2001238 & Positive regulation of extrinsic apoptotic signaling pathway & IMP & No \\
\hline NANOG & GO:0008283 & Cell proliferation & IMP & $(50)$ \\
\hline NOP2 & GO:0008284 & Positive regulation of cell proliferation & TAS & $(53)$ \\
\hline \multirow[t]{3}{*}{ TNFRSF1A } & GO:0006915 & Apoptotic process & TAS & No \\
\hline & GO:0042981 & Regulation of apoptotic process & IEA & No \\
\hline & GO:0043123 & 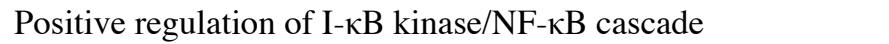 & IEP & (37) \\
\hline
\end{tabular}

GO, gene ontology; Ref., reference; IDA, inferred directly from assay; IEA, inferred from electronic assay; ISS, inferred from sequence or structural similarity; TAS, traceable author statement; IMP: inferred from mutate phenotype; IPI, inferred from physical interaction. ${ }^{a}$ Did not co-occur in liver cancer.

ically interacted, and/or shared protein domains and pathways with each other and a number of other proteins, such as CCND3, CDK4, CDK6, CD44, ITGA2, ITGA3, ITGB1, ESRRB, EGR1, PITX2, REST, CDKN2C and WEE1 (Table V). Therefore, it can be suggested that OY-TES-1, NANOG, CDCA3, CD9 and CCND2 may be functionally related. Although OY-TES-1 was considerably less interactive with other proteins involving in cell proliferation, adhesion, migration and apoptosis in comparing the results, it contains a Kazal-2 domain that could bind with the homeobox domain shared by NANOG and PITX2. Thus, we added interactions between OY-TES-1, NANOG and PITX2, and predicted these interactions with cell proliferation, adhesion, motility and apoptosis in liver cancer. Based on the annotated functions in accordance with the GeneMANIA network, OY-TES-1, NANOG, CD9, CCND2 and CDCA3, along with other proteins listed in Table $\mathrm{V}$, may play important roles in the regulation of cell adhesion, the cell cycle, kinase activity, apoptosis (or anoikis) and DNA binding.

\section{Discussion}

Functional prediction of genes/proteins based on bioinformatic analysis is a feasible and valuable technique for the mining of gene/protein functions, and many large-scale networks of protein interactions within the cell have made it possible to multi-dimensionally study the functions in the context of a network (57). Thus, mining and exploring potentially OY-TES1-interacting genes via bioinformatic methods would be a first, necessary, feasible and reasonable way to reveal its function in liver cancer. Based on the motif, co-expression profile, GO and literature co-occurrence analysis, we found 60 genes to be co-expressing with OY-TES-1 in liver cancer, and 9 out of 60 of these genes are involved in cell proliferation, adhesion (migration) and/or apoptosis. OY-TES-1 and 8 out of 9 genes were found to co-occur in liver cancer, and these 8 genes co-occur with each other. Furthermore, with RNAi and oligonucleotide microarray analysis, we confirmed that, of these 9 genes, expression of CD9, CCND2 and CDCA3 was significantly increased, and NANOG was markedly decreased. The expression levels of the other 5 genes did not change when OY-TES-1 was suppressed in liver cancer cells ( $p>0.05$, Table IV). GeneMANIA network analysis demonstrated that OY-TES-1, NANOG, CD9, CCND2 and CDCA3 were co-expressed, co-localized, physically and genetically interacted and/or shared protein domains and pathways with each other (Fig. 3). Annotated functions (Table V) suggested that OY-TES-1 may 
Table IV. Expression profile of OY-TES-1 co-expressing candidate genes and their interacing genes by OY-TES-1 suppression in the cell line BEL-7404 .

Gene symbol Gene name $\quad$ Biological function of encoded protein $\quad$ Fold-change P-value

OY-TES-1 co-expressing candidate genes

CD9 CD9 molecule

CCND2 Cyclin D2

CDCA3 Cell division cycle associated 3

NANOG Nanog homeobox

TNFRSF1A Tumor necrosis factor receptor superfamily, member $1 \mathrm{~A}$

NOP2 NOP2 nucleolar protein homolog

ING4 Inhibitor of growth family, member 4

LTBR Lymphotoxin $\beta$ receptor

CD27 CD27 molecule
Negative regulation of cell proliferation; suppressor of cancer cell motility and metastasis

Positive regulation of cell proliferation. Regulatory subunit of CDK4 or CDK6, required for cell cycle $\mathrm{G}_{1} / \mathrm{S}$ transition

F-box-like protein required for entry into mitosis.

Acts by participating in E3 ligase complexes that mediate the ubiquitination and degradation of WEE1 kinase at $\mathrm{G}_{2} / \mathrm{M}$ phase

Transcription regulator involvesin embryo stem (ES) cells proliferation and self-renewal. When overexpressed, promotes cells to enter into $S$ phase and proliferation

Major receptor for the tumor necrosis factor- $\alpha$, mediate apoptosis by activating NF- $\kappa \mathrm{B}$

Positive regulation of cell proliferation; increase nucleolar activity associated with cell proliferation

Tumor suppressor protein, involves in the 2.2263 $2.00 \mathrm{E}-04$

2.0956 0.0017

2.0355 0.0208 TP53-dependent regulatory pathway; negative regulation of cell proliferation, positive regulation of apoptotic process

Receptor for heterotrimeric lymphotoxin and TNFS14/LIGHT. Promotes apoptosis via TRAF3 and TRAF5

Receptor for CD70/CD27L. Negative regulation of cysteine-type endopeptidase activity involved in apoptotic process

Interacting genes of OY-TES-1-co-expressing candidate genes

\begin{tabular}{|c|c|c|c|c|}
\hline CCND3 & Cyclin D3 & $\begin{array}{l}\text { Regulatory component of the cyclin } \mathrm{D} 3-\mathrm{CDK} 4 \\
(\mathrm{DC}) \text { complex that inhibits members of the } \\
\text { retinoblastoma }(\mathrm{RB}) \text { protein family, and } \\
\text { regulates the cell-cycle during } \mathrm{G}_{1} / \mathrm{S} \text { transition }\end{array}$ & 1.4241 & 0.0032 \\
\hline CDK6 & $\begin{array}{l}\text { Cyclin-dependent } \\
\text { kinase } 6\end{array}$ & $\begin{array}{l}\text { Serine/threonine-protein kinase involved in the } \\
\text { control of the cell cycle and differentiation; } \\
\text { promotes } \mathrm{G}_{1} / \mathrm{S} \text { transition; negatively regulates } \\
\text { cell differentiation }\end{array}$ & 1.2173 & 0.0205 \\
\hline WEE1 & WEE1 homolog & $\begin{array}{l}\text { Negative regulator of entry into mitosis } \\
\left(\mathrm{G}_{2} \text { to } \mathrm{M} \text { transition) by protecting the }\right. \\
\text { nucleus from cytoplasmically activated } \\
\text { cyclin } \mathrm{B} 1 \text {-complexed CDK } 1\end{array}$ & 1.5128 & 0.0031 \\
\hline $\mathrm{CD} 44$ & CD44 molecule & $\begin{array}{l}\text { Receptor for hyaluronic acid (HA) and possibly } \\
\text { matrix metalloproteinases (MMPs). Adhesion with } \\
\text { HA plays an important role in cell migration, } \\
\text { tumor growth and progression }\end{array}$ & 1.2606 & 0.0055 \\
\hline ITGA2 & Integrin, $\alpha 2$ & $\begin{array}{l}\text { Receptor for laminin, collagen, collagen C-propeptides, } \\
\text { fibronectin and E-cadherin. It is responsible for } \\
\text { adhesion of platelets and other cells, modulation of } \\
\text { collagen and collagenase gene expression }\end{array}$ & 2.1047 & 0.0084 \\
\hline
\end{tabular}


Table IV. Continued.

\begin{tabular}{|c|c|c|c|c|}
\hline Gene symbol & Gene name & Biological function of encoded protein & Fold-change & P-value \\
\hline ITGB1 & Integrin, $\beta 1$ & $\begin{array}{l}\text { Membrane receptors involved in cell adhesion and } \\
\text { recognition in a variety of processes including } \\
\text { embryogenesis, hemostasis, tissue repair, immune } \\
\text { response and metastatic diffusion of tumor cells }\end{array}$ & 1.2910 & 0.0297 \\
\hline ITGA5 & Integrin, $\alpha 5$ & $\begin{array}{l}\text { Receptor for fibronectin and fibrinogen. } \\
\text { Enhance angiogenesis in Kaposi's sarcoma } \\
\text { lesions when HIV-I infected }\end{array}$ & 2.0167 & 0.0029 \\
\hline EGR1 & $\begin{array}{l}\text { Early growth } \\
\text { response } 1\end{array}$ & $\begin{array}{l}\text { Transcriptional regulator recognizes and binds to } \\
\text { EGR-site. Activates the transcription of target } \\
\text { genes whose products are required } \\
\text { for mitogenesis and differentiation }\end{array}$ & 2.3115 & $1.00 \mathrm{E}-04$ \\
\hline
\end{tabular}

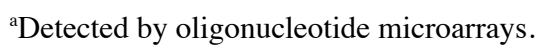

Table V. The biologic process annotated functions of OY-TES 1-co-expressing proteins and their interacting proteins in the GeneMANIA network.

\begin{tabular}{|c|c|c|}
\hline GO annotation & FDR (n/a) & Genes/proteins in the network \\
\hline Cyclin-dependent protein kinase holoenzyme complex & $2.93 \mathrm{E}-05$ & CCND2, CCND3, CDK4, CDK6 \\
\hline Cell-matrix adhesion & $1.47 \mathrm{E}-03$ & CD9, CD44, CDK6, ITGA2, ITGA3, ITGB 1 \\
\hline Cell-substrate adhesion & $5.14 \mathrm{E}-03$ & CD9, CD44, CDK6, ITGA2, ITGA3, ITGB1 \\
\hline Transcription regulatory region sequence-specific DNA binding & $1.77 \mathrm{E}-02$ & NANOG, ESRRB, EGR1, PITX2, REST \\
\hline $\mathrm{G}_{1}$ phase $/ \mathrm{G}_{1}$ phase of mitotic cell cycle & $6.28 \mathrm{E}-02$ & $\mathrm{CDKN} 2 \mathrm{C}, \mathrm{CDK} 4, \mathrm{CDK} 6$ \\
\hline $\begin{array}{l}\text { Regulation of cyclin-dependent protein serine/threonine } \\
\text { kinase activity }\end{array}$ & $1.46 \mathrm{E}-01$ & CCND2, CCND3, CDKN2C \\
\hline $\mathrm{G}_{1} / \mathrm{S}$ transition of mitotic cell cycle & $1.68 \mathrm{E}-01$ & CDCA3, CDK6, CDK4, WEE1, CDKN2C \\
\hline Negative regulation of anoikis & $2.06 \mathrm{E}-01$ & ITGB1, ITGA5 \\
\hline
\end{tabular}

GO, gene ontology; FDR, false discovery rate.

participate in tumor cell proliferation, migration, invasion and apoptosis through regulation of CCND2, CDCA3, CD9 and NANOG.

Both CCND2 and CDCA3 are $\mathrm{G}_{1}$ phase controlling genes. CCND2 overexpression is associated with the tumorigenesis and progression of various types of cancers including liver cancers by affecting the cell cycle, particularly in the $\mathrm{G}_{1}$ phase $\left(G_{1}\right.$ cell cycle transition) with $G_{1}$ CCND2/cyclin-dependent kinase (CDK)4 (or 6) complexes (58-61). Exhibiting a difference with CCND2, CDCA3 can increase the capacity of proliferation by preventing $\mathrm{G}_{1}$ arrest via decreased expression of the CDK inhibitor (CDKI) $(62,63)$. In the present study, downregulation of OY-TES-1 in BEL-7404 cells was accompanied by an increase in CCND2 and CDCA3 as well as their interacting genes CCND3 and CDK6 $(\mathrm{p}<0.05$, Table IV, Fig. 3), which are able to accelerate cell proliferation by promoting $\mathrm{G}_{1} / \mathrm{S}$ transition, $\mathrm{CDK}$ activity regulation or cyclin/CDK complex formation $(60,61,64)$. However, as a negative regulator of entry into mitosis $\left(G_{2}\right.$ to $M$ transition) (65), WEE1 was significantly increased $(\mathrm{p}<0.05)$ (Table IV, Fig. 3); the other cell cycle involved genes CD4 and CDKN2C were not altered (data not shown). Therefore, it is reasonable to infer that downregulation of OY-TES-1 may accelerate the cell cycle and promote proliferation in liver cancer cells through increased expression of CCND2, CDCA3 and their interacing genes CCND3 and CDK6.

CD9 and NANOG are also thought to be associated with the malignant behavior of cells. The absence and low expression of CD9 in small cell lung cancer may contribute to the highly invasive and metastatic phenotype, while ectopic expression of CD9 reduced cell proliferation and motility, attenuated metastasis $(66,67)$ and promoted apoptosis $(68,69)$. Therefore, CD9 has been regarded as an important tumor progression suppressor (70). To date, there is paucity in the research of the correlation between CD9 and liver cancer. As regard to NANOG, it is one of the most important core markers of cancer stem cells (CSCs) due to its capacity to maintain pluripotency, regulate proliferation and prevent differentiation $(71,72)$. NANOG-positive CSCs in liver cancer exhibit drug resistance and a high capacity for tumor invasion 


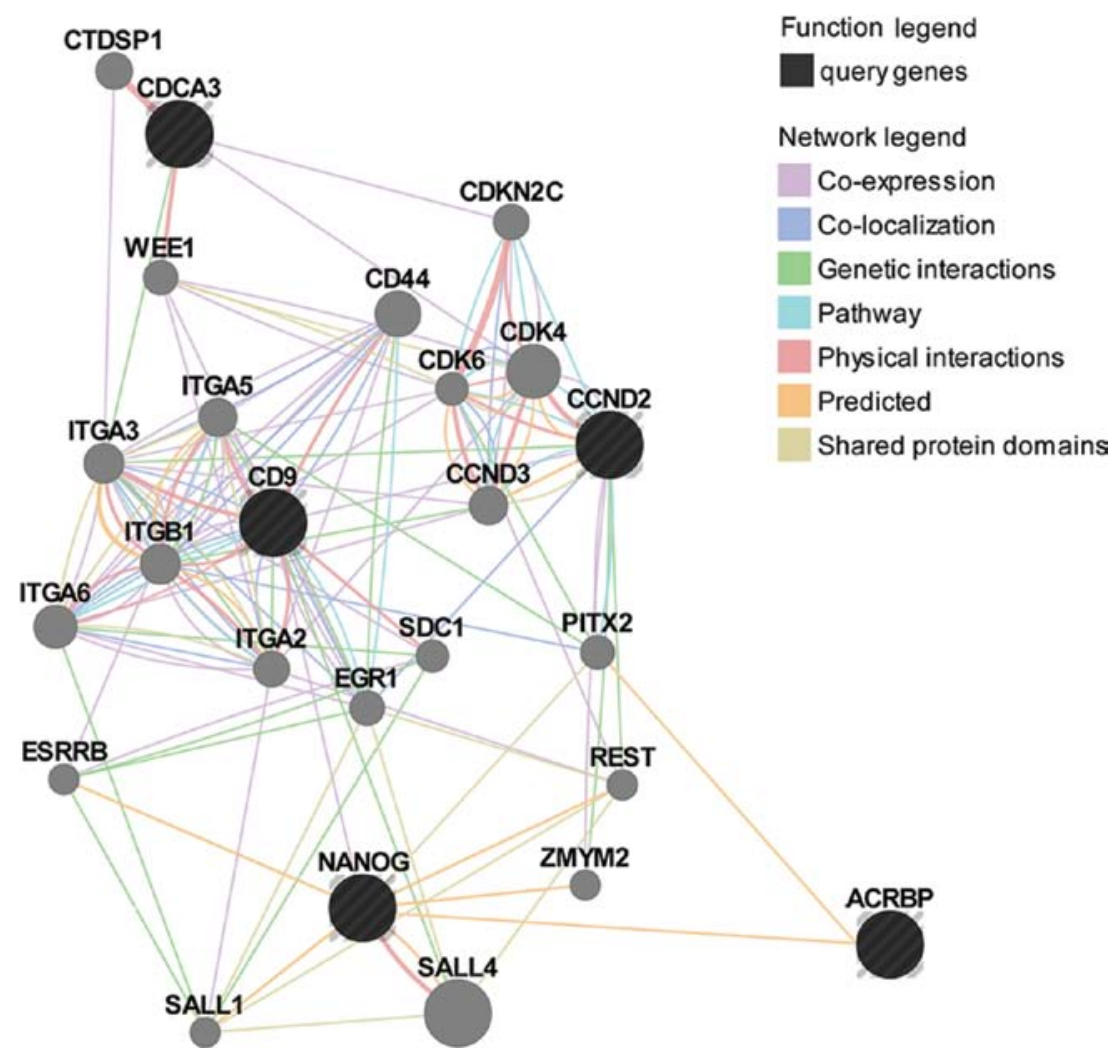

Figure 3. Function prediction of OY-TES-1 (ACRBP) and OY-TES-1-co-expressing proteins using GeneMANIA. The type of interaction between genes/proteins is illustrated as indicated in the network legend.

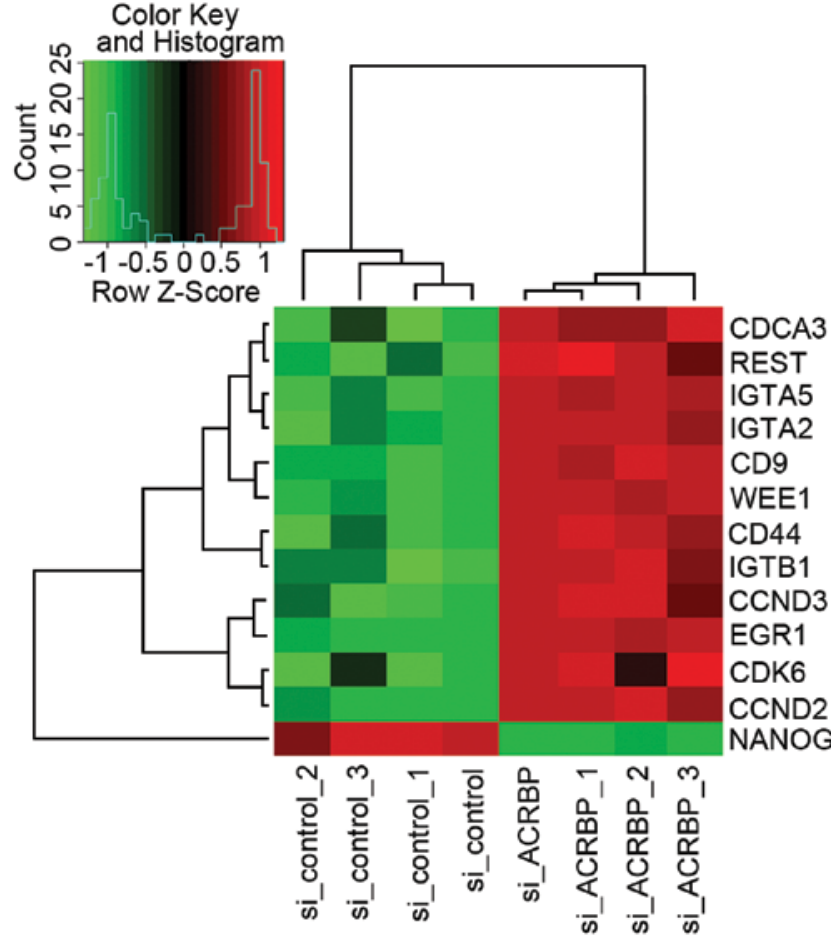

Figure 4. Transcriptional profiling of OY-TES-1 (ACRBP)-associated genes between 3 independent $\mathrm{Si}$ _control and 3 independent Si_OY-TES-1 groups of the BEL-7404 cell line, as detected using Agilent oligonucleotide microarray. $\mathrm{Si}_{-}$control and $\mathrm{Si}_{-}$OY-TES-1 are the average of 3 independent $\mathrm{Si}$ _control and 3 independent Si_OY-TES-1 groups, respectively. Highly expressed genes are shown in red, whereas genes that are expressed at lower levels compared with the $\mathrm{Si}_{-}$control group are displayed in green. A brighter color means a greater difference from the $\mathrm{Si}$ _control group compared with a darker color. ACRBP, acrosin binding protein.

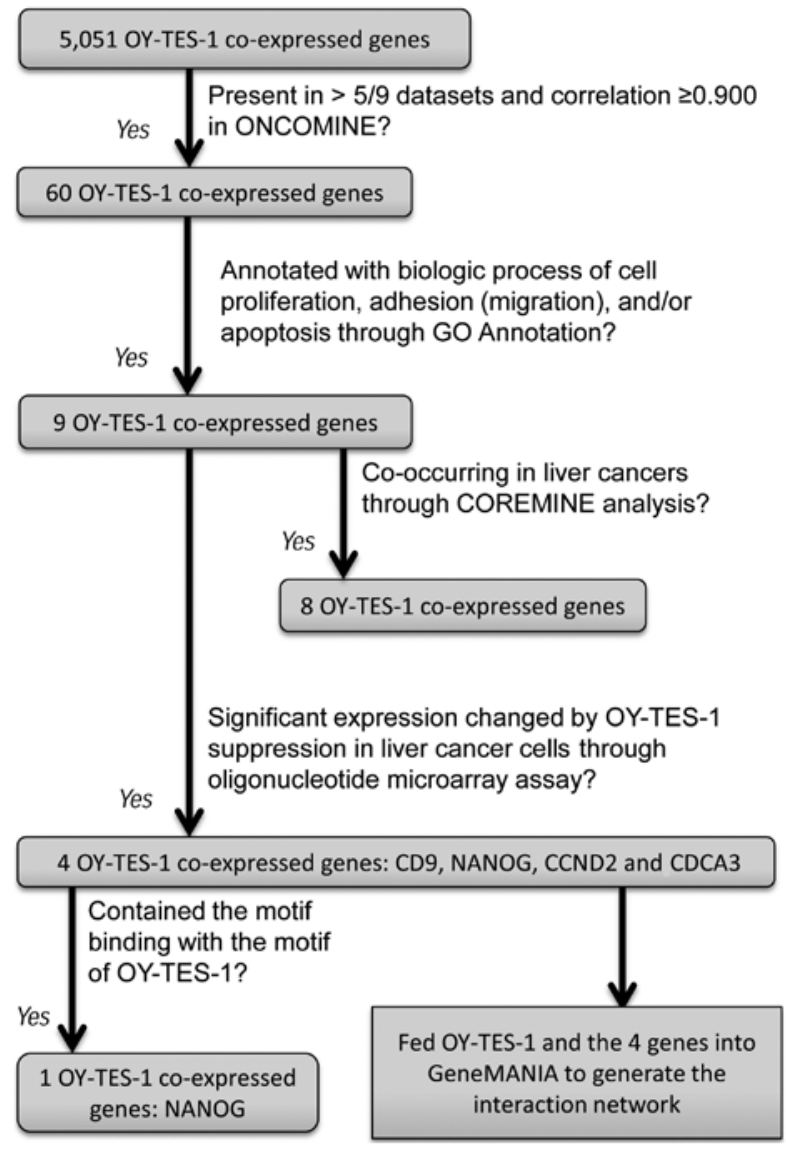

Figure 5. Workflow for selecting OY-TES-1-interacting protein candidates in liver cancers through bioinformatic methods and oligonucleotide microarray assay. 
and metastasis $(73,74)$. The same situation is present in other cancers. For example, upregulation of NANOG enhances malignant behaviors in esophageal cancer $(52,75)$; adversely, its downregulation causes inhibitive effects on ovarian and gastric cancer (76). Here, we demonstrated that suppression of OY-TES-1 in a cancer cell line significantly increased expression of CD9 and its interacting genes (CD44, ITGA2, ITGB1 and ITGA5), which negatively regulate proliferation and migration in cancer cells (40-43). Meanwhile, we also found a decrease in NANOG and elevation in EGR1 which interacts with NANOG (Fig. 4; Table IV). EGR1 is thought to be a cancer suppressor (77). There was no change in the other genes listed in Table $\mathrm{V}$, which are involved in cell differentiation and proliferation and are related with CD9 or NANOG. Notably, in the present study downregulation of OY-TES-1 in liver cancer cells caused two opposite effects, namely, promotion of cell proliferation with increase in CCND2 and CDCA3, and inhibition of cell proliferation with CD9 upregulation and NANOG downregulation. Therefore, it was speculated that OY-TES-1 may play multiple roles in liver cancer. Experiments should be conducted to elucidate the function of OY-TES-1 with CD9, NANOG, CCND2, CDCA3 and their interacted proteins in the future.

Collectively, as shown in Fig. 5, we first report that OY-TES-1 suppression results in significant expression changes of its co-expressing genes, CCND2, CDCA3, CD9 and NANOG. As it contains a Kazal-2-interacting motif, homeobox, NANOG may be considered to be the most likely candidate protein interacting with OY-TES-1 in liver cancer. Thus, the present study may set the stage for further investigation of the role of OY-TES-1 in liver cancer.

\section{Acknowledgements}

We thank Ms. Fang Chen, Ms. Chengxiao Chen from Guangxi Medical University for their excellent technical assistance. The present study was supported by the National Natural Science Foundation of China (nos. 81360371, 30760055 and 81360374), the Natural Science Foundation of Guangxi (nos. 2011GXNSFA018275 and 2014GXNSFAA118172), and the Innovative Project for Postgraduate of Guangxi Educational Bureau (nos. YCBZ2013017 and YCSZ2014103).

\section{References}

1. Mo QG, Liang AM, Yang NW, et al: Surgery-predominant comprehensive therapy for 134 patients with small hepatocellular carcinoma. Ai Zheng 22: 189-191, 2003 (In Chinese).

2. Yoon $\mathrm{H}, \mathrm{Lee} \mathrm{H}, \mathrm{Kim} \mathrm{HJ}$, et al: Tudor domain-containing protein 4 as a potential cancer/testis antigen in liver cancer. Tohoku J Exp Med 224: 41-46, 2011

3. Song MH, Choi KU, Shin DH, et al: Identification of the cancer/ testis antigens AKAP3 and CTp11 by SEREX in hepatocellular carcinoma. Oncol Rep 28: 1792-1798, 2012.

4. Xing Q, Pang XW, Peng JR, et al: Identification of new cytotoxic T-lymphocyte epitopes from cancer testis antigen HCA587. Biochem Biophys Res Commun 372: 331-335, 2008.

5. Zhao L, Mou DC, Leng XS, et al: Expression of cancer-testis antigens in hepatocellular carcinoma. World J Gastroenterol 10: 2034-2038, 2004.

6. Pang PH, Chan KT, Tse LY, et al: Induction of cytotoxic T cell response against HCA661 positive cancer cells through activation with novel HLA-A $* 0201$ restricted epitopes. Cancer Lett 256 178-185, 2007.
7. Yang XA, Dong XY, Qiao H, et al: Immunohistochemical analysis of the expression of FATE/BJ-HCC-2 antigen in normal and malignant tissues. Lab Invest 85: 205-213, 2005.

8. Yin YH, Li YY, Qiao H, et al: TSPY is a cancer testis antigen expressed in human hepatocellular carcinoma. Br J Cancer 93: 458-463, 2005.

9. Ono T, Kurashige T, Harada N, et al: Identification of proacrosin binding protein $\mathrm{sp} 32$ precursor as a human cancer/testis antigen. Proc Natl Acad Sci USA 98: 3282-3287, 2001.

10. Fan R, Huang W, Xiao SW, et al: OY-TES-1 expression and serum immunoreactivity in hepatocellular carcinoma. World Chi J Digest 17: 3307-3312, 2009 (In Chinese).

11. Tammela J, Uenaka A, Ono T, et al: OY-TES-1 expression and serum immunoreactivity in epithelial ovarian cancer. Int $\mathrm{J}$ Oncol 29: 903-910, 2006.

12. Whitehurst AW, Xie Y, Purinton SC, et al: Tumor antigen acrosin binding protein normalizes mitotic spindle function to promote cancer cell proliferation. Cancer Res 70: 7652-7661, 2010.

13. Kanemori Y, Ryu JH, Sudo M, et al: Two functional forms of $\mathrm{ACRBP} / \mathrm{sp} 32$ are produced by pre-mRNA alternative splicing in the mouse. Biol Reprod 88: 105, 2013.

14. Okumura H, Noguchi Y, Uenaka A, et al: Identification of an HLA-A24-restricted OY-TES-1 epitope recognized by cytotoxic T-cells. Microbiol Immunol 49: 1009-1016, 2005.

15. Cen YH, Guo WW, Luo B, et al: Knockdown of OY-TES-1 by RNAi causes cell cycle arrest and migration decrease in bone marrow-derived mesenchymal stem cells. Cell Biol Int 36: 917-922, 2012.

16. Yellaboina S, Tasneem A, Zaykin DV, et al: DOMINE: a comprehensive collection of known and predicted domain-domain interactions. Nucleic Acids Res 39: D730-D735, 2011.

17. Finn RD, Bateman A, Clements J, et al: Pfam: the protein families database. Nucleic Acids Res 42: D222-D230, 2014.

18. Kumar B, Sharma D, Sharma P, et al: Proteomic analysis of Mycobacterium tuberculosis isolates resistant to kanamycin and amikacin. J Proteomics 94: 68-77, 2013.

19. Rhodes DR, Kalyana-Sundaram S, Mahavisno V, et al: Oncomine 3.0: genes, pathways, and networks in a collection of 18,000 cancer gene expression profiles. Neoplasia 9: 166-180, 2007.

20. Wilson BJ and Giguère V: Identification of novel pathway partners of p68 and p72 RNA helicases through Oncomine metaanalysis. BMC Genomics 8: 419, 2007.

21. Li Z, Ma B, Lu M, et al: Construction of network for protein kinases that play a role in acute pancreatitis. Pancreas 42: 607-613, 2013.

22. Melaiu O, Cristaudo A, Melissari E, et al: A review of transcriptome studies combined with data mining reveals novel potential markers of malignant pleural mesothelioma. Mutat Res 750: 132-140, 2012.

23. Smith IM, Glazer CA, Mithani SK, et al: Coordinated activation of candidate proto-oncogenes and cancer testes antigens via promoter demethylation in head and neck cancer and lung cancer. PLoS One 4: e4961, 2009.

24. Suyama T, Shiraishi T, Zeng Y, et al: Expression of cancer/testis antigens in prostate cancer is associated with disease progression. Prostate 70: 1778-1787, 2010.

25. Warde-Farley D, Donaldson SL, Comes O, et al: The GeneMANIA prediction server: biological network integration for gene prioritization and predicting gene function. Nucleic Acids Res 38: W214-W220, 2010.

26. Williamson MP, Marion D and Wüthrich K: Secondary structure in the solution conformation of the proteinase inhibitor IIA from bull seminal plasma by nuclear magnetic resonance. J Mol Biol 173: 341-359, 1984

27. Laskowski M Jr, Kato I, Ardelt W, et al: Ovomucoid third domains from 100 avian species: isolation, sequences, and hypervariability of enzyme-inhibitor contact residues. Biochemistry 26: 202-221, 1987.

28. Schlott B, Wöhnert J, Icke C, et al: Interaction of Kazal-type inhibitor domains with serine proteinases: biochemical and structural studies. J Mol Biol 318: 533-546, 2002.

29. Funk JD, Nedialkov YA, Xu D and Burton ZF: A key role for the $\alpha 1$ helix of human RAP74 in the initiation and elongation of RNA chains. J Biol Chem 277: 46998-47003, 2002.

30. Baba T, Niida Y, Michikawa Y, et al: An acrosomal protein, sp32, in mammalian sperm is a binding protein specific for two proacrosins and an acrosin intermediate. J Biol Chem 269: 10133-10140, 1994. 
31. Hase H, Kanno Y, Kojima H, et al: CD27 and CD40 inhibit p53-independent mitochondrial pathways in apoptosis of B cells induced by B cell receptor ligation. J Biol Chem 277: 46950-46958, 2002.

32. Shi JY, Gao Q, Wang ZC, et al: Margin-infiltrating CD $20^{+} \mathrm{B}$ cells display an atypical memory phenotype and correlate with favorable prognosis in hepatocellular carcinoma. Clin Cancer Res 19: 5994-6005, 2013.

33. Wang XD, Wang L, Ji FJ, et al: Decreased CD27 on B lymphocytes in patients with primary hepatocellular carcinoma. J Int Med Res 40: 307-316, 2012.

34. Yang ZQ, Yang ZY, Zhang LD, et al: Increased liver-infiltrating $\mathrm{CD}^{+}{ }^{+} \mathrm{FoxP} 3^{+}$regulatory $\mathrm{T}$ cells are associated with tumor stage in hepatocellular carcinoma patients. Hum Immunol 71: 1180-1186, 2010.

35. Zhang X, Xu LS, Wang ZQ, et al: ING4 induces G2/M cell cycle arrest and enhances the chemosensitivity to DNA-damage agents in HepG2 cells. FEBS Lett 570: 7-12, 2004

36. Doyon Y, Cayrou C, Ullah M, et al: ING tumor suppressor proteins are critical regulators of chromatin acetylation required for genome expression and perpetuation. Mol Cell 21: 51-64, 2006.

37. Li X, Cai L, Chen H, et al: Inhibitor of growth 4 induces growth suppression and apoptosis in glioma U87MG. Pathobiology 76: 181-192, 2009.

38. Karabulut B, Karaca B, Atmaca H, et al: Regulation of apoptosisrelated molecules by synergistic combination of all-trans retinoic acid and zoledronic acid in hormone-refractory prostate cancer cell lines. Mol Biol Rep 38: 249-259, 2011.

39. Matsuda A, Suzuki Y, Honda G, et al: Large-scale identification and characterization of human genes that activate NF- $\kappa \mathrm{B}$ and MAPK signaling pathways. Oncogene 22: 3307-3318, 2003.

40. Masellis-Smith A and Shaw AR: CD9-regulated adhesion. Anti-CD9 monoclonal antibody induces pre-B cell adhesion to bone marrow fibroblasts through de novo recognition of fibronectin. J Immunol 152: 2768-2777, 1994.

41. Leung KT, Chan KY, Ng PC, et al: The tetraspanin CD9 regulates migration, adhesion, and homing of human cord blood CD34 hematopoietic stem and progenitor cells. Blood 117: 1840-1850, 2011.

42. Powner D, Kopp PM, Monkley SJ, et al: Tetraspanin CD9 in cell migration. Biochem Soc Trans 39: 563-567, 2011.

43. Kanetaka K, Sakamoto M, Yamamoto Y, et al: Overexpression of tetraspanin CO-029 in hepatocellular carcinoma. J Hepatol 35 637-642, 2001

44. Li J and Li G: Cell cycle regulator ING4 is a suppressor of melanoma angiogenesis that is regulated by the metastasis suppressor BRMS1. Cancer Res 70: 10445-10453, 2010.

45. Meyerson $M$ and Harlow $E$ : Identification of $G_{1}$ kinase activity for cdk6, a novel cyclin D partner. Mol Cell Biol 14: 2077-2086, 1994.

46. Yadav S, Pandey A, Shukla A, et al: miR-497 and miR-302b regulate ethanol-induced neuronal cell death through BCL2 protein and cyclin D2. J Biol Chem 286: 37347-37357, 2011.

47. Zhou J, Tian Y, Li J, et al: miR-206 is down-regulated in breast cancer and inhibits cell proliferation through the up-regulation of cyclinD2. Biochem Biophys Res Commun 433: 207-212, 2013.

48. Zhang L, Liu X, Jin H, et al: miR-206 inhibits gastric cancer proliferation in part by repressing cyclinD2. Cancer Lett 332: 94-101, 2013

49. Chen BB, Glasser JR, Coon TA, et al: F-box protein FBXL2 targets cyclin D2 for ubiquitination and degradation to inhibit leukemic cell proliferation. Blood 119: 3132-3141, 2012.

50. Igawa T, Sato Y, Takata K, et al: Cyclin D2 is overexpressed in proliferation centers of chronic lymphocytic leukemia/small lymphocytic lymphoma. Cancer Sci 102: 2103-2107, 2011.

51. Dong Q, Meng P, Wang T, et al: MicroRNA let-7a inhibits proliferation of human prostate cancer cells in vitro and in vivo by targeting E2F2 and CCND2. PLoS One 5: e10147, 2010.

52. Darr H, Mayshar Y and Benvenisty N: Overexpression of NANOG in human ES cells enables feeder-free growth while inducing primitive ectoderm features. Development 133: 1193-1201, 2006.

53. Yang L, Zhang X, Zhang M, et al: Increased Nanog expression promotes tumor development and cisplatin resistance in human esophageal cancer cells. Cell Physiol Biochem 30: 943-952, 2012.

54. Siu MK, Wong ES, Kong DS, et al: Stem cell transcription factor NANOG controls cell migration and invasion via dysregulation of E-cadherin and FoxJ1 and contributes to adverse clinical outcome in ovarian cancers. Oncogene 32: 3500-3509, 2013.
55. Valdez BC, Perlaky L, Saijo Y, et al: A region of antisense RNA from human p120 cDNA with high homology to mouse p120 cDNA inhibits NIH 3T3 proliferation. Cancer Res 152: 5681-5686, 1992.

56. Siggers RH and Hackam DJ: The role of innate immune-stimulated epithelial apoptosis during gastrointestinal inflammatory diseases. Cell Mol Life Sci 68: 3623-3634, 2011.

57. Sharan R, Ulitsky I and Shamir R: Network-based prediction of protein function. Mol Syst Biol 3: 88, 2007.

58. Dodurga Y, Oymak Y, Gündüz C, et al: Leukemogenesis as a new approach to investigate the correlation between up regulated gene 4/upregulator of cell proliferation (URG4/URGCP) and signal transduction genes in leukemia. Mol Biol Rep 40: 3043-3048, 2013

59. Faussillon M, Monnier L, Junien C and Jeanpierre C: Frequent overexpression of cyclin D2/cyclin-dependent kinase 4 in Wilms tumor. Cancer Lett 221: 67-75, 2005.

60. Park TJ, Chun JY, Bae JS, et al: CCND2 polymorphisms associated with clearance of HBV infection. J Hum Genet 55: 416-420, 2010.

61. Takano Y, Kato Y, van Diest PJ, et al: Cyclin D2 overexpression and lack of p27 correlate positively and cyclin E inversely with a poor prognosis in gastric cancer cases. Am J Pathol 156: 585-594, 2000.

62. Uchida F, Uzawa K, Kasamatsu A, et al: Overexpression of cell cycle regulator CDCA3 promotes oral cancer progression by enhancing cell proliferation with prevention of G1 phase arrest. BMC Cancer 12: 321, 2012.

63. Chen J, Zhu S, Jiang N, et al: HoxB3 promotes prostate cancer cell progression by transactivating CDCA3. Cancer Lett 330: 217-224, 2013.

64. Bunt J, de Haas TG, Hasselt NE, et al: Regulation of cell cycle genes and induction of senescence by overexpression of OTX2 in medulloblastoma cell lines. Mol Cancer Res 8: 1344-1357, 2010.

65. Visconti R, Palazzo L, Della Monica R and Grieco D: Fep1dependent dephosphorylation is required for M-phase-promoting factor inactivation at mitosis exit. Nat Commun 3: 894, 2012

66. Funakoshi T, Tachibana I, Hoshida Y, et al: Expression of tetraspanins in human lung cancer cells: frequent downregulation of CD9 and its contribution to cell motility in small cell lung cancer. Oncogene 22: 674-687, 2003.

67. Ovalle S, Gutiérrez-López MD, Olmo N, et al: The tetraspanin CD9 inhibits the proliferation and tumorigenicity of human colon carcinoma cells. Int J Cancer 121: 2140-2152, 2007.

68. Saito Y, Tachibana I, Takeda Y, et al: Absence of CD9 enhances adhesion-dependent morphologic differentiation, survival, and matrix metalloproteinase-2 production in small cell lung cancer cells. Cancer Res 66: 9557-9565, 2006.

69. Murayama Y, Miyagawa J, Oritani K, et al: CD9-mediated activation of the $\mathrm{p} 46 \mathrm{Shc}$ isoform leads to apoptosis in cancer cells. J Cell Sci 117: 3379-3388, 2004.

70. Zheng R, Yano S, Zhang H, et al: CD9 overexpression suppressed the liver metastasis and malignant ascites via inhibition of proliferation and motility of small-cell lung cancer cells in NK cell-depleted SCID mice. Oncol Res 15: 365-372, 2005.

71. Kim JS, Kim J, Kim BS, et al: Identification and functional characterization of an alternative splice variant within the fourth exon of human nanog. Exp Mol Med 37: 601-607, 2005.

72. Oh JH, Do HJ, Yang HM, et al: Identification of a putative transactivation domain in human Nanog. Exp Mol Med 37: 250-254, 2005.

73. Shan J, Shen J, Liu L, et al: Nanog regulates self-renewal of cancer stem cells through the insulin-like growth factor pathway in human hepatocellular carcinoma. Hepatology 56: 1004-1014, 2012.

74. Sun C, Sun L, Jiang K, et al: NANOG promotes liver cancer cell invasion by inducing epithelial-mesenchymal transition through NODAL/SMAD3 signaling pathway. Int J Biochem Cell Biol 45: 1099-1108, 2013

75. Du Y, Shi L, Wang T, Liu Z and Wang Z: Nanog siRNA plus Cisplatin may enhance the sensitivity of chemotherapy in esophageal cancer. J Cancer Res Clin Oncol 138: 1759-1767, 2012.

76. Ji W and Jiang Z: Effect of shRNA-mediated inhibition of Nanog gene expression on the behavior of human gastric cancer cells. Oncol Lett 6: 367-374, 2013.

77. Yu J, Zhang SS, Saito K, et al: PTEN regulation by Akt-EGR1ARF-PTEN axis. EMBO J 28: 21-33, 2009. 